\title{
The role of graded category structure in imaginative thought
}

\author{
THOMAS B. WARD, MERRYL J. PATTERSON, CYNTHIA M. SIFONIS, \\ REBECCA A. DODDS, and KATHERINE N. SAUNDERS \\ Texas A\&M University, College Station, Texas
}

\begin{abstract}
Participants generated lists of exemplars from the categories of animals, tools, and fruit, and their lists were used to determine the relative accessibility of individual exemplars. Measures of accessibilityincluded output dominance (the number of participants who listed an exemplar), rank (how early instances were listed), and two scores that reflect their combination-output precedence and dominance/rank. Other participants drew and described novel exemplars of those categories that might exist on an imaginary planet and reported on the factors that influenced their creations. References to Earth animals, tools, or fruit were used to determine imagination frequency (the number of participants who mentioned relying on particular Earth exemplars). Items high in accessibility were also high in imagination frequency, implying that those items that come to mind most readily are the ones most likely to serve as starting points for the development of novel ideas. This result held even when task constraints weighed against the use of such items (Experiment 2) and when participants were encouraged to be as creative as possible (Experiment 4), suggesting that it is difficult to avoid the influence of highly accessiblecategory exemplars. Other measures of category structure, including the rated typicality, familiarity, and frequency of exemplars, did not predict imagination frequency as well. The results are discussed in terms of expanding concept boundaries and the inadvertent application of knowledge that is readily accessible.
\end{abstract}

Generating new ideas is an important and pervasive human activity. Whether to solve practical problems, satisfy esthetic desires, or simply innovate for its own sake, people are constantly about the business of creating something new. Architects design new buildings, writers dream up new villains, engineers develop new mechanical devices, and homemakers concoct new recipes. What these and many other generative activities have in common is that they are all instances of conceptual expansion (Ward, Smith, \& Vaid, 1997), in which people extend the boundaries of a conceptual domain by mentally crafting novel instances of the concept. When an architect drafts plans for a new building, he or she is generating a new instance of a familiar concept (e.g., high-rise apartment building). When an author writes about a new villain, he or she is adding yet another instance to a well-known domain from literature, and so on.

Because conceptual expansion involves the generation of new instances of existing concepts, it is not surprising that newly generated ideas tend to resemble the old ones from which they spring. Rubin and Kontis (1983), for example, asked participants to develop designs for novel

This material is based on work supported by the National Science Foundation under Grant BCS-9983424. The authors thank Steve Smith and three anonymous reviewers for their comments on earlier versions of this paper. Correspondence should be addressed to T. B. Ward, Department of Psychology, Texas A\&M University, College Station, TX $77843-$ 4235 (e-mail: tbw@psyc.tamu.edu).

-Accepted by previous editorial team coins and found striking similarities between those designs and the attributes of known coins. Although the participants were instructed not to be creative or silly, that admonition does not seem to have been the critical determinant of their conformity to existing instances. Ward (1994), for example, had participants develop novel animals for the imaginary setting of a distant planet and still found their creations to possess characteristic attributes of Earth animals, such as eyes, legs, and bilateral symmetry, even when they were asked to use their wildest imagination. Ward and Sifonis (1997) also found similar results when participants were explicitly instructed to make creatures that were wildly different from Earth animals. Nor is the resemblance between new and old ideas limited to laboratory studies of college students. The origin and form of many real-world creative accomplishments can also be traced to the knowledge available to their creators (see, e.g., Basalla, 1988; Ward, Finke, \& Smith, 1995; Ward et al., 1997; Weisberg, 1986, 1993), suggesting that even the products of highly creative individuals are heavily structured by their existing concepts.

This tendency for novel ideas to be structured in predictable ways by existing conceptual frameworks is referred to as structured imagination (Ward, 1994, 1995). It is a robust tendency that has also been observed in young normal children (Cacciari, Levorato, \& Cicogna, 1997; KarmiloffSmith, 1990) and gifted adolescents (Ward, Saunders, \& Dodds, 1999), as well as science fiction authors (Ward, 1994), design engineers (Condoor, Brock, \& Burger, 1993), and other creative individuals (Ward, 1995; Ward et al., 1995). The phenomenon has also been shown to extend to a variety of conceptual domains, such as imaginary 
faces (Bredart, Ward, \& Marczewski, 1998) and restaurants (Sifonis, 1995).

The impact of category knowledge is also revealed by the fact that novel creations can be influenced by recently encountered category examples even when people are instructed to avoid copying properties of those examples. This is true of design engineers developing ideas for new spill-proof cups and measuring devices for the blind (Jansson \& Smith, 1991) and of college students imagining new toys, carpets, extraterrestrial animals, and category labels (Marsh, Landau, \& Hicks, 1996; Marsh, Ward, \& Landau, 1999; Sifonis, Ward, Gentner, \& Houska, 1997; Smith, Ward, \& Schumacher, 1993).

Thus, there is little doubt that existing concepts constrain and direct the form of newly developed ideas, a notion inherent in many views of creativity (e.g., Perkins, 1981, 1988; Schank \& Cleary, 1995). Indeed, there is a trivial sense in which this must be so. What could new ideas be based on if not existing knowledge? Beyond establishing the basic fact that new ideas are shaped by old ones, therefore, it is important to delineate the specific properties of existing conceptual structures that are particularly influential in guiding imaginative thought. In the present experiments, we examined one such property-namely, graded category structure - and assessed the extent to which the influence of known category instances is predictable from their representativeness within the category of interest.

The focus on representativeness stems from the pathof-least-resistance model (Ward, 1994, 1995), which attributes the resemblance between newly generated entities and known ones to the approach people take in generating those novel entities. The model proposes that, although people can adopt a variety of strategies for developing new ideas, a predominant approach is to retrieve specific known instances of the relevant concept and to project the properties of those instances onto the novel idea. Furthermore, the selection of instances is assumed to be guided by their representativeness. Items that are the most representative of the concept are the ones most likely to be retrieved and used as starting points for new ideas. In generating an imaginary animal, for example, a person would tend to move toward a level of abstraction more specific than animal and to gravitate toward representative instances, such as mammal and $d o g$, rather than less representative ones, such as fish or bat. These specificity and representativeness assumptions are examined in the present experiments.

Representativeness can be conceptualized and measured in several distinct ways, including obtaining ratings of how typical an entity is of its category, how closely it approximates the central tendency of the category, how well it satisfies ideals, and how frequent or familiar it seems (Barsalou, 1985). Although each of these measurable aspects of representativeness might be expected to play a role in how the category is used in different situations, the property that we assume to be most important to creative generation is retrievability or "coming-to-mindedness"that is, how readily an instance comes to mind when the category name is given as a cue. The prediction from the path-of-least-resistance is that the more readily a given instance comes to mind when a concept is activated, the more likely it is that the item will be used as a starting point in developing a new idea. This focus on coming-to-mindedness reflects the intuition that generative tasks demand considerable cognitive resources and that one way to simplify the task is to quickly settle on a model, any model, as a starting point. Whatever comes to mind first and to most people is most likely to be used.

An item's retrievability could well be influenced by and interrelated with other indicators of its representativeness, such as its judged typicality, frequency of occurrence, familiarity, and so on. That is, it might be that more typical, frequent, or familiar instances are the ones that are most readily retrieved in response to the category name. Likewise, gradations in retrievability could be the result of the way in which a concept is constructed at a given point in time from stored information, recent experiences, and the current context. It need not be viewed as an invariant property of a concept's structure (see Barsalou, 1987, for a similar observation regarding typicality). Nevertheless, it is an observable property of category instances that, when the category is activated or constructed, the resulting representation will be structured in such a way that some of those instances will be retrieved more readily than others. Those gradations in retrievability are expected to influence imaginative activities differentially.

The present paper reports a set of experiments designed to test this representativeness assumption using three conceptual domains: animals, tools, and fruit. For each domain, separate groups of participants performed a listing task and a creative generation task. In the listing task, the participants simply wrote down the first 20 real instances they could think of for each category. From those lists, we determined retrievability indices for each item by assessing the frequency with which given items were listed (termed output dominance), their average rank order of appearance across participants' lists (termed rank), and two measures that combined frequency and rank order (termed output precedence and dominance/rank). In the creative generation task, the participants conceived and drew novel instances of the category that would be appropriate to an imaginary setting. Of most interest was the extent to which the measures of retrievability predicted the likelihood that particular instances would play a role in imaginative generation and the extent to which those relationships were resistant to changes in task constraints and instructions. An additional experiment attempted to differentiate between the influence of coming-to-mindedness and other measures of the representativeness of instances within categories, such as typicality and familiarity.

\section{EXPERIMENT 1}

\section{Experiment 1A: Listing Real Earth Animals}

\section{Method}

Participants. Thirty undergraduate students enrolled in introductory psychology classes participated as one of several means of sat- 
isfying a course requirement. All participants gave informed consent and were debriefed following participation.

Materials and Procedure. Each participant received a sheet of paper containing instructions to list the first 20 animals that came to mind. The sheet also included 20 lines on which the participants were to list their responses. The participants were tested in small groups of about 5 , and each participant was allowed as much time as needed to complete the task.

Coding. All individual listings of any Earth creature (living or extinct) were noted. Adapting procedures used by Barsalou (1985) and Battig and Montague (1969), except for clear misspellings, minor variants in inflection (e.g., $\operatorname{dog}$ and $\operatorname{dog} s$ ), and colloquial variations (e.g., hippo for hippopotamus), all nonidentical items were treated as distinct entities (e.g., bear and polar bear remained as separate entries). Output dominance was determined for each of the listed Earth animals and was defined as the number of participants who listed a given animal. Each distinct instance was also coded for rank, defined as the average output position across all lists on which the instance appeared. Although output dominance and rank are group measures, the former can reasonably serve as an index of the likelihood that an instance will come to mind for a given individual, and the latter can serve as an index of how quickly it will come to mind when it does so. Output precedence was computed by assigning each item that appeared on a list a number corresponding to the reverse of its list position (by subtracting its position from 21). Items not appearing on a given participant's list were counted as 0 for that list. By summing the values for each item across participants, the result reflects the combined influence of frequency of listing and output position, with larger values indicating a greater accessibility. Dominance/rank was simply output dominance divided by average rank. To the extent that instances come quickly to mind to large numbers of participants, they will receive high output precedence and dominance/rank scores.

\section{Results}

The participants listed a total of 147 distinct Earth animals. Output dominance for these items ranged from 28 (for cat) to 1. Appendix A includes each item that was listed by 3 or more participants, along with the output dominance, rank, output precedence, and dominance/rank scores for each item. ${ }^{1}$ Appendix A also includes additional animals and scores to be described later.

\section{Experiment 1B: Generating Imaginary Animals}

\section{Method}

Participants. Seventy-one individuals from the same introductory psychology participant pool as in Experiment 1A took part in Experiment 1B. None had participated in the animal listing task.

Design and Procedure. The participants were asked to imagine a planet very different from Earth on which many species of plants and animals existed. They were further asked to imagine encountering a member of one of those species of animals and to draw it in a way that would allow a naive observer to recognize it from the drawing. The participants were also instructed to label all of the creature's major parts and to provide a label or name for the creature as a whole.

After turning in their labeled drawings, the participants were given new response sheets on which they wrote open-ended statements about the factors that influenced the development of their creatures. They were encouraged to try to recount anything that might have influenced them. Drawings were removed prior to this task to reduce the possibility that the participants would look at the drawings, notice a similarity to an Earth animal, and list that animal as a source of their ideas even though it had not come to mind during the idea generation task.
Coding. Two coders examined each drawing for the presence of standard Earth animal senses (i.e., eyes, ears, noses, and mouths) and appendages (i.e., arms, legs, wings, and fins), as well as for the property of symmetry. They also assigned a global rating of originality to each creature, using a 7-point scale intended to reflect the extent to which creatures diverged from typical Earth animals. On this scale, 1 indicated that the creature was identical to some Earth animal, and 7 indicated that the creature was completely different from any Earth animal; in general, higher numbers indicated more originality. The coders had percent agreement scores of 85 or better for each of the categorical variables and a correlation of .823 between their originality ratings.

The coders then noted explicit references to specific Earth animals in the labels that the participants applied to their drawings, as well as in their statements about the factors that influenced their creations. Such references could include statements about whole animals or their parts. These statements were examined after and separately from the assessments of the drawings to reduce the possibility that the coders' judgments about the drawings would be influenced by their judgments about the statements, and vice versa. Any mention of a specific Earth animal was counted unless (1) the participant made an explicit statement that, after thinking about the Earth animal, he or she attempted to avoid the influence of that animal or (2) the participant's statement indicated a simple recognition, after the fact, that the creature resembled some Earth animal. These types of statements were not consistent with the idea that the participant had used the creature as one of the sources of the novel idea. Imagination frequency was determined for each specif ic Earth animal mentioned and was defined as the number of participants who mentioned that animal.

Although the participants' reports about the factors that influenced their creations were retrospective, it is important to note that such reports have been found to correspond well to the properties of the participants' drawings. For instance, when asked to develop feathered extraterrestrials, the participants who subsequently reported a reliance on birds were significantly more likely than those who reported other approaches to develop creatures that possessed birdlike properties (Ward, 1994). This correspondence between reported approaches and the details of the participants' creations suggests that retrospective reports of having relied on specific types of Earth animals can be taken as reasonably accurate reflections of the participants' having done so.

The coders also examined statements for references to other influences, such as science fiction books and movies. However, as in previous studies (Ward, 1994), those references did not predominate, occurring in only $19 \%$ of the statements. References to Earth animals were considerably more common, and since the focus of the present paper was on the relation between the representativeness of animals in the Earth animal category and the reported use of Earth animals in a task of imagination, only references to Earth animals were analyzed further.

\section{Results and Discussion}

Reports of Earth animal use. Forty-five of the 71 participants $(63 \%)$ in Experiment 1B (creature generation task) mentioned the influence of one or more specific Earth animals. An additional 3 participants mentioned relying on particular Earth animals, but they failed to specify the exact animals or made reference to broad classes of Earth animals (e.g., mammals). Thus, just over two thirds of the sample mentioned the influence of Earth animals. The participants mentioned relying on a total of 32 distinct Earth animals in generating their imaginary creatures. Only three of those animals (goldfish, pterodactyl, and 
Table 1

Correlations Between Output Dominance (OD), Rank, Output Precedence (OP), Dominance/Rank (OD/R), and Imagination Frequency for the Full Set of Animals and for Selected Subsets Retrievability Measure

\begin{tabular}{lccccc}
\cline { 3 - 6 } \multicolumn{1}{c}{ Set } & Number & OD & Rank & OP & OD/R \\
\hline Full & $150(147)$ & $.486^{*}$ & -.051 & $.524^{*}$ & $.527^{*}$ \\
OD 15 & 13 & $.589^{*}$ & $-.665^{*}$ & $.658^{*}$ & $.714^{*}$ \\
OD 5 & 32 & $.681^{*}$ & $-.574^{*}$ & $.719^{*}$ & $.705^{*}$ \\
Nonhuman & $149(146)$ & $.674^{*}$ & $-.195^{*}$ & $.725^{*}$ & $.715^{*}$ \\
\hline
\end{tabular}

Note-The number of pairs in the full set for the correlation between rank and imagination frequency was 147 rather than 150 , because the full set of 150 included 3 items that had not been listed in the Earth animal listing task and therefore had no meaningful rank information. Their lack of occurrence in the listing task can be meaningfully represented as 0 for the other measures, and thus they could be included in computing the correlations involving those measures. Correspondingly, the number of pairs for the rank / imagination frequency correlation was 146 rather than 149 when human was removed from the full set of 150 pairs. *Significant at or beyond the .05 level.

slug) had not been mentioned by participants in the Earth animal listing task. Imagination frequency ranged from 12 to 1 . That is, the most commonly used Earth animal was listed by 12 of the 71 participants in the creature generation task. Imagination frequency for each animal mentioned is shown in Appendix A.

Of most interest was the relation between imagination frequency and the measures of representativeness: output dominance, rank, output precedence, and dominance/rank. The relevant correlations for the entire set of animals listed in the Earth animal listing task (Experiment 1A), the creature generation task (Experiment 1B), or both are depicted in the first row of Table 1 . As can be seen, imagination frequency was significantly positively correlated with all of the measures except rank, to which it appeared largely unrelated. Thus, measures that incorporate the frequency with which specific Earth animals come to mind in response to the category cue appear to be better predictors of their use in imagination than how quickly the animals come to mind.

One concern in interpreting this pattern of correlations, however, is that, because they were computed on the full set of items, many instances were included that were low in output dominance. Rank is especially susceptible to idiosyncratic influences for such items, and including them could have introduced enough extraneous variability to make it difficult to detect correlations involving that variable. For instance, an animal listed by just one participant in the Earth animal listing task (Experiment 1A), and listed first would receive an "average" rank of 1 , whereas the same item listed last would receive an average rank of 20 . Items listed by larger numbers of participants are less susceptible to extreme influences of this kind from the output order of any one participant. An additional concern about using the full set of animals is that the correlation between output dominance and imagination frequency might have been influenced by the fact that a large num- ber of items in the full set had output dominance scores of 1 and imagination frequency scores of 0 .

To determine whether the absence of a correlation between rank and imagination frequency was an artifact of using the full set of items, we computed two additional correlation coefficients, eliminating the potentially problematic low output dominance items. We eliminated items with output dominance lower than 5 in one case and lower than 15 in the other. As can be seen in the second and third rows of Table 1, in each case, the correlation between rank and imagination frequency was negative and significant, indicating that the instances of animals that are listed earliest when people consider Earth animals are the ones that are most likely to be used as a basis for developing imaginary extraterrestrial animals. Thus, the failure to detect a correlation between rank and imagination frequency for the full set may have been due to the fact that rank is of limited value as a measure for items low in output dominance.

Also shown in Table 1 is the fact that the correlation between output dominance and imagination frequency remained positive, of moderate size, and significant across the smaller sets compared. Thus, the significant correlation found between those variables for the full set of animals is not simply an artifact of including a large number of instances that have an output dominance of 1 and an imagination frequency of 0 . Likewise, the correlations between output precedence, dominance/rank and imagination frequency remained significant for those more restrictive sets.

Although the correlations for output precedence and dominance/rank tended to be higher than those for output dominance and rank, most were moderate in size, providing evidence that each of the measures had some utility in predicting imagination frequency. There is, however, evidence that the measures that incorporate both dominance and rank information predict variance in imagination frequency beyond either of those measures alone. The partial correlation between output precedence and imagination frequency, controlling for both output dominance and rank, was positive and significant $[r(143)=.289, p<.001]$, as was the comparable partial correlation between dominance/ rank and imagination frequency $[r(143)=.307, p<.001]$. Taken together, the pattern of correlations suggests that the more likely a given animal is to come to mind in response to the category label, and the faster it comes to mind, the more likely it is to be used by participants who are given the task of imagining animals that might exist on another planet.

The human effect. An interesting exception to the general pattern of high retrievability being associated with greater use in imagination is the instance human. Only 1 participant (out of 30) listed human as an example of the category animal, whereas 12 (out of 71) reported that they had based their imaginary creature on humans. Indeed, humans were used more than any other animal as a basis for an imaginary creature. Put differently, humans were overrepresented in the imagination task relative to their representativeness in the Earth animal category. We con- 
sider several interpretations of this unexpected finding in the General Discussion section. For now, we simply note that, when human is deleted from the full set of items, the correlations between the retrievability measures and imagination frequency are substantially increased, relative to those computed on the full set, including human (see last row of Table 1).

Creature attributes. Although our major focus was on the reported use of Earth creatures as the bases for the participants' imagined extraterrestrials, we also noted the properties of the creatures themselves. The vast majority contained at least one standard sense organ (99\%), at least one standard appendage (97\%), and the property of bilateral symmetry (91\%); those percentages did not differ significantly between participants who did versus those who did not report relying on specific Earth animals [largest $\chi^{2}$ $(1, N=71)=1.33, p>.24]$. The percentages were comparable to ones reported in previous research (Ward, 1994; Ward \& Sifonis, 1997) and were consistent with the idea that, regardless of specific conditions and reported approaches to the task, people have a striking tendency to include those characteristic features of Earth animals in their imagined extraterrestrials.

Despite those global similarities across nearly all of the imagined creatures, there were differences associated with variations in the participants' reported approaches to the task. Specifically, extraterrestrials generated by the participants who reported relying on particular Earth animals received significantly lower originality scores than those generated by the other participants $(M \mathrm{~s}=3.18$ and 4.34 , respectively) $[t(69)=2.81, p<.01]$. Put differently, the participants who claimed to have based their extraterrestrials on Earth animals produced creatures that more closely resembled Earth animals - a finding that lends credibility to their reports. Because the drawings and reported approaches were coded separately, it is unlikely that this relationship was based simply on the coders' ratings of drawing being influenced by their tabulations of references to Earth animals, and vice versa. The result also supports the assumption of the path-of-least-resistance model that people project the properties of retrieved instances onto their imagined entities. Projecting the properties of specific known animals would be expected to result in creations that closely resemble Earth animals.

\section{EXPERIMENT 2}

The retrievability of exemplars from the Earth animal category was found to be positively correlated with the reported use of those exemplars in an imaginative generation task. This finding allows a statement beyond the simple and obvious case that knowledge affects imagination. Rather, a particular aspect of category structure-namely, exemplar retrievability-determines the likelihood that specific aspects of conceptual structure will influence imagination. Items that come to mind more quickly to more people are the ones most likely to be used as sources of information for the development of new ideas.
In Experiment 2, we sought to extend the generality of the findings with regard to exemplar retrievability to another domain (tools), and we examined the extent to which its influence is resistant to task constraints. In Experiment 1 , the participants were free to imagine any creature they could, with no constraints on what it could look like, in what type of environment it might survive, and so on. It is possible that they gravitated toward Earth animals because those animals provided an easy solution to the task and did not violate any specified constraints. In Experiment 2, we required some of the participants to imagine tools for a species very unlike humans in that they had no appendages. One hypothesis is that, because manipulation by way of hands is a central property of standard tools, constraining participants to consider such a creature might encourage them to move away from Earth tool exemplars. Alternatively, however, the tendency to rely on highly retrievable exemplars of the domain may be strong enough that it remains even when those exemplars would need to be heavily modified to meet task constraints. By this latter view, participants facing the constraint may be just as likely as unconstrained participants to rely on Earth tool models, and they will simply modify those exemplars to meet the needs of the species.

\section{Experiment 2A: Listing Real Earth Tools}

\section{Method}

Participants. Thirty introductory psychology students from the same source as in Experiments 1A and 1B participated. None had taken part in the previous experiments.

Procedure. The procedural details were identical to those in Experiment $1 \mathrm{~A}$, except that the participants listed the first 20 tools they could think of. Output dominance, rank, output precedence, and dominance/rank for individual tools were determined in the same manner as in Experiment 1A.

\section{Results}

The participants listed a total of 188 distinct tools. Output dominance ranged from 28 (for hammer) to 1 . The complete list of tools with output dominance of three or greater is shown in Appendix B along with output dominance, rank, dominance/rank, and output precedence for each instance. Data for several additional tools and devices, as described later, are also shown in Appendix B.

\section{Experiment 2B: Generating Imaginary Tools}

\section{Method}

Participants. One-hundred thirty-five students from the same introductory psychology pool as in Experiments 1A and 1B participated. None had been in the previous experiments.

Design and Procedure. The participants were asked to imagine tools that might be used by an intelligent species of extraterrestrials. They were further instructed to think of tools that would not be operated by electricity or other power sources. Sixty-six of the participants were given no special information about the creature other than its intelligence. The remaining 69 participants were told that the creature had no arms, legs, or other appendages comparable to those of Earth animals. The intent was to force them to imagine tools that would 
Table 2

Correlations Between Output Dominance (OD), Rank, Output Precedence (OP), Dominance/Rank (OD/R), and Imagination Frequency for the Full Set of Tools and for Selected Subsets

\begin{tabular}{lcllll}
\hline & & \multicolumn{4}{c}{ Retrievability Measure } \\
\cline { 3 - 6 } Set & Number & OD & Rank & OP & OD/R \\
\hline Full & 201 & $.615^{*}$ & $-.213^{*}$ & $.661^{*}$ & $.769^{*}$ \\
OD 15 & 6 & .780 & -.745 & $.868^{*}$ & $.985^{*}$ \\
OD 5 & 26 & $.549^{*}$ & $-.393^{*}$ & $.592^{*}$ & $.549^{*}$ \\
\hline
\end{tabular}

Note-The number of pairs in the full set for the correlation between rank and imagination frequency was 188 rather than 201, because the full set of 201 included 13 items that had not been listed in the Earth tool listing task and therefore had no meaningful rank information. Their lack of occurrence in the listing task can be meaningfully represented as 0 for the other measures, and thus they could be included in computing the correlations involving those measures. "Significant at or beyond the .05 level.

meet the needs of a specific target creature, rather than allowing them to develop tools with no constraints. After completing their drawings, the participants labeled the tool, gave a brief description of its use and the materials from which it was made, and wrote openended statements about any factors that influenced their thinking while developing the idea for the tool.

Two coders assessed the properties of the tools, such as the presence of handles and blades, and rated the originality of each tool on a 7-point scale, with higher numbers indicating greater originality. The coders then tabulated explicit statements referring to specific Earth tools, which were used to determine imagination frequency scores for individual instances of tools. Statements were considered to refer to Earth tools if they included a reference to any of the tools noted in the Earth tool listing task (Experiment 2A) or if they clearly fell into the category of implements designed to aid human activities, such as food preparation and agriculture. Coder agreement exceeded $85 \%$ for each categorical variable, and originality ratings were positively correlated $(r=.710)$.

\section{Results}

Reports of reliance on Earth tools. Collapsing across conditions (control vs. no appendages), 92 of the 135 participants (68\%) mentioned specific Earth tools. Considering the conditions separately, $64 \%$ of the control participants and $72 \%$ of those in the no-appendages condition relied on specific Earth tools. Because those percentages did not differ substantially, and because the pattern of correlations between imagination frequency and the measures of exemplar retrievability did not differ across the conditions, those correlations will be reported collapsed across groups. We simply note here that requiring the participants to consider a species that had no appendages did not decrease their tendency to rely on Earth tools, nor did it affect their tendency to rely most heavily on tools that are more retrievable.

The participants reported reliance on 50 distinct Earth tools, and imagination frequency ranged from 23 (for ham$m e r)$ to 1 . Of that set of tools, 13 were ones that had not been mentioned in the Earth tool listing task, and these included fruit corer, dicer, juicer, laser, lever, lightbulb remover, plow, scooper, scraper, scythe, straw, trowel, and tweezers. Thus, in comparison with the participants who relied on only three extralist animals in developing their imaginary extraterrestrials, the participants developing imaginary tools appear to have diverged somewhat more from the listings we obtained for standard Earth tools. However, consistent with the results for animals, the correlations between output dominance, rank, output precedence, dominance/rank, and imagination frequency reveal a link between item retrievability and the use of items in imagination. Table 2 shows the correlations for the full set of items and for items with output dominance of at least 5 or at least 15 . Note that, although the correlations were of moderate size, they were not significant for the measures of output dominance and rank with imagination frequency for the set of items with output dominance of 15 or more. This is not surprising, however, given the low number of pairs (6) involved in the comparison. In addition, using a one-tailed criterion (which may be more appropriate given that the hypothesis about retrievability was a directional one), even those correlations were significant.

As in the case of animals, partial correlations between output precedence and imagination frequency and between dominance/rank and imagination frequency were significant when controlling for both output dominance and $\operatorname{rank}[r(184)=.337, p<.001$, and $r(184)=.586, p<$ .001 , respectively]. In addition, those who mentioned specific Earth tools generated imaginary tools that were rated as significantly lower in originality than those who did not $(M \mathrm{~s}=3.03$ and 4.18 , respectively) $[t(133)=4.25, p<.001]$. Thus, again, a reported reliance on Earth models was associated with developing imaginary products that diverged less from known category instances.

Data on imagined tools. Although the participantsin the no-appendages condition did not differ from those in the control conditionin the tendency to rely on real Earth tools, they did impose modifications needed to make the tools usable by the species they were asked to consider. Specifically, they were significantly less likely to include handles on their imagined tools ( $23 \%$ vs. $73 \%)\left[\chi^{2}(1, N=\right.$ $135)=33.20, p<.001]$. They solved the problem of how the creature would use the tool by more often including alternative devices, such as mouth pieces (39\% vs. $1 \%$ ) $\left[\chi^{2}(1, N=135)=29.03, p<.001\right]$ or harnesses to attach the tool to the head or body $(20 \%$ vs. $3 \%)\left[\chi^{2}(1, N=135)=\right.$ $9.62, p<.01]$. Thus, rather than abandoning exemplars of highly retrievable instances of the Earth tool category, the participants who were constrained to think about a creature without appendages used standard Earth tools and modified them appropriately. Examples of tools including the modifications are shown in Figure 1.

\section{EXPERIMENT 3 Other Measures of Representativeness}

According to the path-of-least-resistance model, when people imagine novel entities, they tend to rely on known category instances that come to mind most readily. Although the correlations between the retrievability of ex- 


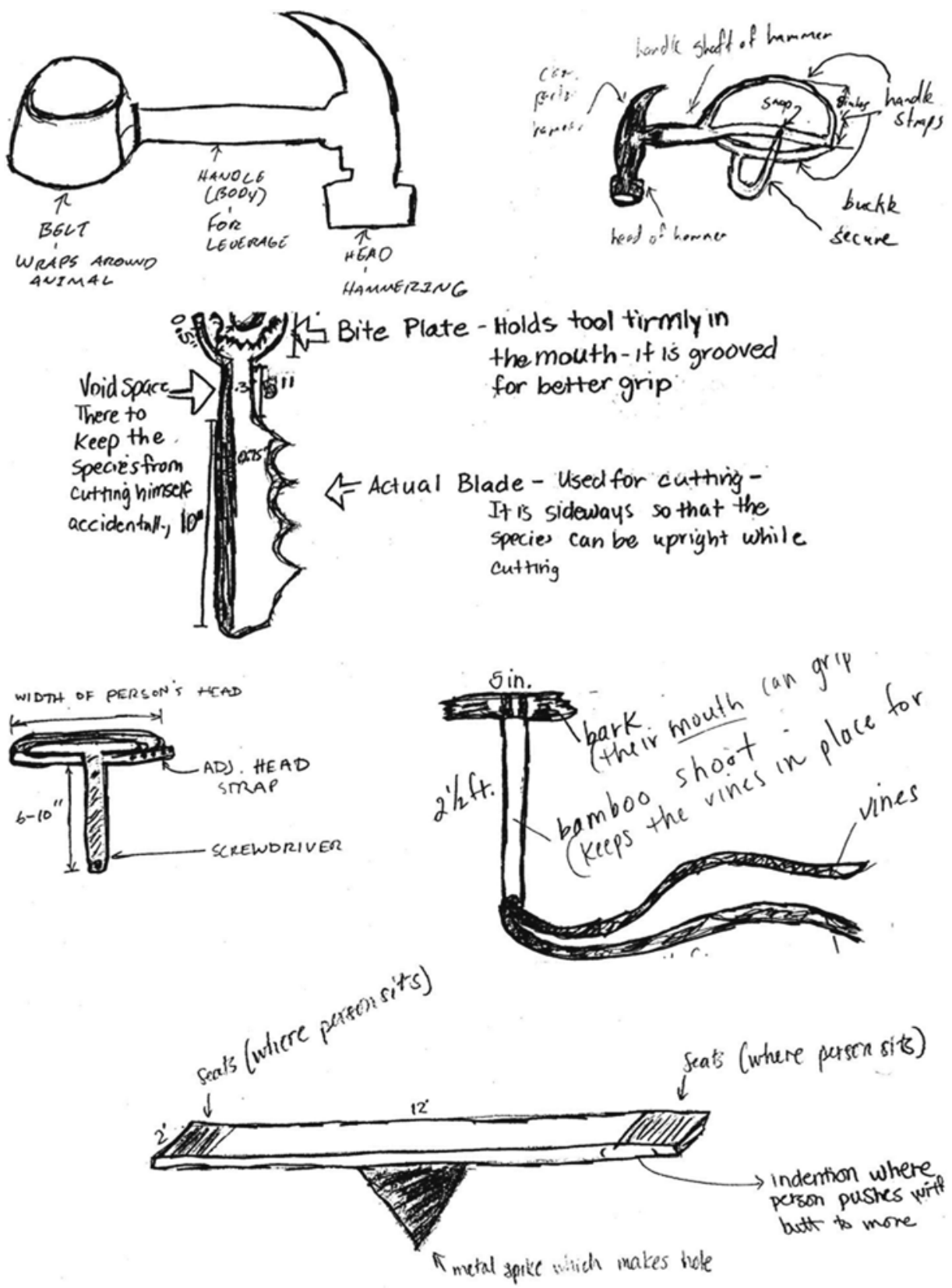

Figure 1. Examples of imaginary tools generated by participants in the no-appendages condition.

emplars and their reported use in imagination found in the first two experiments were consistent with this view, it is by no means certain from those findings that retrievability is the only, or even the most influential, property of category representativeness. The obtained correlations might be the result of retrievability being an indirect measure of another aspect of graded category structure, such as typicality. Furthermore, even if retrievability independently accounts for some amount of variance in imaginative tasks, it may be a smaller amount of variance than for other measures. In Experiment 3, we examined these issues.

As an alternative to immediately adopting the first idea that comes to mind, people might, for a variety of reasons, consider other possible models and gravitate toward those that seem most typical of the category, most familiar, and most pleasing, and that satisfy some ideal or meet some other criterion. For instance, because the generative task represents a kind of communication between the participant 
Table 3

Raw and Partial Correlations of Dominance/Rank (OD/R), Typicality, Similarity, Familiarity, Frequency, Liking, and Centrality to Human Concerns With Imagination Frequency for the Category of Animals

\begin{tabular}{lcc}
\hline & \multicolumn{2}{c}{ Type of Correlation } \\
\cline { 2 - 3 } Variable & Raw & Partial \\
\hline OD/R & $.682^{*}$ & $.595^{*}$ \\
Typicality & -.010 & -.196 \\
Similarity & .078 & -.084 \\
Familiarity & $.468^{*}$ & .211 \\
Frequency & $.366^{*}$ & .151 \\
Liking & .188 & -.019 \\
Centrality & $.257^{*}$ & -.024 \\
\hline
\end{tabular}

Note-For raw correlations, $d f=67$. The partial correlation of OD/R with imagination frequency controlled simultaneously for rated typicality, similarity, familiarity, frequency, liking, and importance to humans; for this partial correlation, $d f=61$. The remaining partial correlations controlled for OD/R; for these correlations, $d f=66$. " "Significant at the .05 level or beyond.

and the experimenter, the participant might be concerned with using highly typical or familiar instances to aid that communication. As another example, because the participants were asked to devise only one tool, they might have tried to develop imaginary tools that would be especially useful. Because retrievability might be related to those variables, the correlations observed in the first two experiments could be a result of the variance that output dominance shares with those measures. In Experiment 3, the participants rated animals and tools on several different scales, and we correlated those ratings with the previous measures of imagination frequency.

\section{Method}

Participants. One hundred seventy-six students from the same pool as in Experiments 1 and 2 participated. None had been in any of the previous experiments.

Materials and Design. The participants provided ratings for 70 animals. The set included all of the animals that had been listed by at least 3 participants in Experiment 1A (the Earth animal listing task) or that had been reported as an influence on the development of an imaginary creature by at least 1 participant in Experiment $1 \mathrm{~B}$ (the imaginary animals task). Similarly, the tools to be rated included those with output dominance scores of 3 or more or that had been mentioned by 1 or more of the participants in Experiment 2B (the imaginary tools task). The set of tools was also expanded slightly to include other clearly useful artifacts that had been mentioned by the participants in Experiment 2B but that had not been categorized as tools for analysis purposes in Experiment 2A. This resulted in a total of 89 tools being rated. The additional items were basket, boat, box, cage, drink machine, exercise machine, golf tee, hairbrush, injector, projector, shoe, skateboard, vehicle, wagon, and wheel. Including these items ensured a wide range of ratings and meant that the correlations reported here were influenced by data from $81 \%$ of the participants in Experiment 2B.

Separate groups of participants $(n \mathrm{~s}=16$ each) used 7-point scales to rate the animals on their typicality, familiarity, frequency of occurrence, centrality to human concerns, likeability, and similarity to humans, with larger numbers indicating higher ratings. Following Barsalou (1985), typicality was assessed by instructing the participants to rate how good an example of the category a given exemplar was, familiarity was assessed with instructions that emphasized fa- miliarity to the rater, and frequency was assessed with instructions that emphasized frequency in the world in general. Similarly, separate groups of participants $(n \mathrm{~s}=20 \mathrm{each}$ ) rated each tool on 7-point scales of typicality, familiarity, frequency of occurrence, and usefulness.

\section{Results and Discussion}

Animals. The mean scale values for each animal are shown in Appendix A. Because human represented an unusual item, our analysis here concentrates on the set of animals that were rated, excluding human. ${ }^{2}$ We report on dominance/rank as the measure of retrievability that was compared with the ratings from the present experiment, but comparable findings were obtained with comparisons involving output dominance and output precedence. Correlations between dominance/rank, the present ratings, and imagination frequency are shown in the first column of Table 3. As shown, ratings of typicality, liking, and similarity to humans were not significantly correlated with imagination frequency as measured in Experiment 1B. Also shown is the fact that ratings of familiarity, frequency, and centrality to human concerns were positively correlated with imagination frequency, although the magnitude of those correlations was smaller than that between dominance/ rank and imagination frequency.

More revealing than the raw correlations, however, was an analysis of the pattern of partial correlations, depicted in the second column of Table 3 . As shown, when controlling for dominance/rank, none of the correlations between any of the ratings and imagination frequency was significant. On the other hand, when controlling simultaneously for all six ratings, dominance/rank remained significantly positively correlated with imagination frequency. Similar results were obtained when using a log transformation of dominance/rank as a way of adjusting for positive skewing of that variable that might have given it an advantage in correlating with imagination frequency. The raw correlation with imagination frequency was still significant $[r(67)=.641, p<.001]$, as was the partial correlation when controlling for all six rating variables $[r(61)=.591$, $p<.001]$. None of the ratings was significantly positively related to imagination frequency when controlling for the

Table 4

Raw and Partial Correlations of Dominance/Rank (OD/R),

Typicality, Familiarity, Frequency, and Usefulness With Imagination Frequency for the Category of Tools

\begin{tabular}{llc}
\hline & \multicolumn{2}{c}{ Type of Correlation } \\
\cline { 2 - 3 } Variable & Raw & Partial \\
\hline OD/R & $.741^{*}$ & $.730^{*}$ \\
Typicality & .098 & $-.220^{*}$ \\
Familiarity & $.256^{*}$ & .175 \\
Frequency & $.270^{*}$ & $.230^{*}$ \\
Usefulness & $.248^{*}$ & .118 \\
\hline
\end{tabular}

Note-For raw correlations, $d f=87$. The partial correlation of OD/R with imagination frequency controlled simultaneously for rated typicality, familiarity, frequency, and usefulness; for this partial correlation, $d f=83$. The remaining partial correlations controlled for OD/R; for these correlations, $d f=86$. ${ }^{*}$ Significant at the .05 level or beyond. 
log transformed dominance/rank, and, in fact, typicality was significantly negatively correlated with imagination frequency $[r(66)=-.294, p<.05]$.

Tools. The mean scale values for each tool are shown in Appendix B. Correlations between dominance/rank, the four sets of ratings, and imagination frequency are shown in the first column of Table 4. As shown, the largest correlation was that between dominance/rank and imagination frequency, although frequency, familiarity, and usefulness were positively correlated to a smaller degree with imagination frequency. As in the case of animals, when controlling for dominance/rank, the positive correlations between those ratings and imagination frequency were reduced, although the correlation for rated frequency remained significant, and typicality was negatively correlated with imagination frequency. As can be seen, when controlling for all four ratings simultaneously, dominance/rank remained significantly positively correlated with imagination frequency. As was true for animals, a log transformed version of dominance/rank led to the same pattern of raw and partial correlations.

Together, the results suggest that retrievability, as measured by dominance/rank, predicts the likelihood of an item being used in imagination more strongly than a variety of other measures of category structure, including typicality, familiarity, and frequency of instantiation, as well as ratings of ideals, such as liking and usefulness (see, e.g., Barsalou, 1985).

\section{EXPERIMENT 4 Imaginary Fruit and Task Demands}

The results of Experiments 1-3 established a clear link between the ease with which items come to mind in response to category labels and the tendency to use those items in tasks of imagination. In Experiment 4, we considered the extent to which the results remain the same across another domain —namely, fruit—and across instructional conditions designed to encourage the participants to move away from representative exemplars. Although the prior references to imaginary planets were intended to signal to the participants that creative responses would be appropriate and even desirable, it is possible that they relied on highly retrievable instances in an effort to avoid producing items that would appear too creative or silly. In Experiment 4, we explicitly instructed some participants to be creative, and we instructed others not to feel that they had to pattern their imaginary fruit after instances of Earth fruit.

\section{Method}

Participants. Thirty-six participants from the same pool as in the previous experiments participated in a fruit listing task, and 203 participated in an imaginary fruit generation task. None had been in any of the previous experiments.

Design and Procedure. Following the same procedure as described in Experiments 1A and 2A, 36 participants were asked to list the first 20 fruit that came to mind. Output dominance, rank, output precedence, and dominance/rank were computed as in the previous experiments. Following procedures similar to those in Experiments $1 \mathrm{~B}$ and $2 \mathrm{~B}, 203$ participants were asked to imagine, draw, and describe fruit that might exist on a planet very different from Earth and to indicate the factors that influenced their creations. Two coders rated the participants' creations for originality on a 7-point scale, noted the presence of various characteristic fruit properties (e.g., seeds, juiciness), and tabulated references to specific exemplars of Earth fruit as sources of the imaginary products.

Fifty of the participants who generated ideas for imaginary fruit were asked to be as creative as they could be, and 50 were asked to use their wildest imagination and not "feel bound by what fruit is like on Earth." These will be referred to as the creative and not-bound conditions, respectively. The remaining 103 participants, in the control condition, were given no special instructions about how to approach the task.

\section{Results and Discussion}

The participants in the fruit listing task listed 66 distinct exemplars of real Earth fruit, and output dominance ranged from 36 (for orange) to 1 . A listing of all fruit that were mentioned, along with their corresponding retrievability scores, is presented in Appendix C.

Sixty-six percent of the participants in the control condition of the imaginary fruit generation task mentioned at least one Earth fruit or related item as a source of information for their extraterrestrial fruit. Although that percentage dipped slightly to $62 \%$ in the creative condition, the decline in reliance on Earth fruit was not significant $\left(\chi^{2}<1\right)$. In contrast, $48 \%$ of the participants in the not-bound condition reported a reliance on Earth fruit, which was significantly lower than the percentage for the control group $\left[\chi^{2}(1, N=153)=4.56, p<.05\right]$. Thus, instructions to use one's wildest imagination and not feel bound by what Earth fruit is like appear to have reduced the participants' reliance on exemplars of Earth fruit as models for imaginary fruit. However, even with this significant decline, it is still the case that nearly half of the participants in the not-bound condition reported a reliance on at least one exemplar of Earth fruit. Across the groups, 45 distinct exemplars were mentioned, with 32 being items that appeared in the fruit listing task. The remaining 13 items did not appear in the fruit listing task but were included for analysis purposes because they are technically fruit (berries, dewberry, eggplant, gourd, pepper, and zucchini) or be-

Table 5

Correlations Between Output Dominance (OD), Rank, Output Precedence (OP), Dominance/Rank (OD/R), and Imagination Frequency for the Full Set of Fruit for Each Condition Separately and for the Conditions Combined

\begin{tabular}{llcccc}
\hline & & \multicolumn{4}{c}{ Retrievability Measure } \\
\cline { 3 - 6 } \multicolumn{1}{c}{ Set } & Number & OD & Rank & OP & OD/R \\
\hline Control & $79(66)$ & .622 & -.516 & .785 & .926 \\
Creative & $79(66)$ & .690 & -.517 & .812 & .841 \\
Not bound & $79(66)$ & .637 & -.491 & .750 & .703 \\
Combined & $79(66)$ & .695 & -.554 & .850 & .926 \\
\hline
\end{tabular}

Note-The number of pairs for the correlation between rank and imagination frequency was 66 rather than 79 , because the full set of 79 included 13 items that had not been listed in the Earth fruit listing task and therefore had no meaningful rank information. For the other measures, those items could meaningfully receive scores of 0 and could thus be included in computing the correlations. All correlations were significant beyond the .05 level. 
cause they were highly familiar plant products (corn, flower, green bean, lettuce, onion, peanut, and turnip). Imagination frequency ranged from 35 (for apple) to 1 .

The correlations between imagination frequency and the measures of exemplar retrievability are depicted in Table 5 separately for the three conditions. As is evident, those correlations revealed significant relations between the measures across all of the conditions. The correlations shown in Table 5 are for the full set of fruit mentioned by any participant in either the listing task or the imagination task, but, as in the previous experiments, the same pattern held for correlations computed on smaller sets of items with output dominance scores of at least 5 and 15 (smallest $r=.579$ ). Thus, among those who rely on Earth fruit, the tendency to rely more on fruit that are more readily retrievable was evident in all conditions.

A $2 \times 3$ analysis of variance was computed on originality scores using reported reliance on Earth fruit (yes or no) and condition (control, creative, not bound) as factors. Consistent with results from Experiments 1B and 2B, the analysis revealed a significant effect of Earth fruit $\left[F(1,197)=34.51, M S_{\mathrm{e}}=0.936, p<.001\right]$, indicating that those who reported a reliance on Earth fruit developed creations that were rated as reliably less original than those who did not report a reliance on Earth fruit $(M \mathrm{~s}=$ 2.50 vs. 3.40). The analysis also revealed a significant effect of condition $\left[F(2,197)=5.78, M S_{\mathrm{e}}=0.936, p<.05\right]$, with the means for the creative and not-bound conditions being nearly identical (3.12 vs. 3.16) and the mean for the control condition being lower (2.57). There was no significant interaction $(F<1)$.

\section{GENERAL DISCUSSION}

The results of these experiments yielded a strikingly consistent pattern. Across the three distinct domains of animals, tools, and fruit, roughly two thirds of the participants who were asked to imagine novel instances reported relying on specific known exemplars from those domains. Furthermore, they did so even when confronted with task constraints that might have been expected to militate against the properties of such instances, as in the case of tools for creatures without appendages, and when asked to be as creative as they could be. Although the tendency to rely on specific instances of Earth fruit was reduced somewhat when the participants were instructed to not feel bound by real Earth exemplars, even in that case nearly half of the participants reported a reliance on specific members of the domain. The results support the specificity principle of the path-of-least-resistance model, which states that people will tend to move toward relatively specific levels of conceptual hierarchies to provide a starting point for their new ideas. It should be noted, however, that there are limits to specificity, in that most retrieved items appear to be basic level instances.

Clearly, not all individuals rely on specific instances as starting points for their novel creations. One third of the participants gave no written indication of having done so.
Thus, it is inappropriate to characterize specificity as a rigid constraint on generative processing. Rather, it is a strategic approach, which happens to be dominant. Other approaches are possible, and the nature of the imagined products evidently varies with the person's approach. That is, across all three domains, the participants who did not mention a reliance on specific instances developed creations that were rated as higher in originality or more divergent from the base domain.

The tendency to rely on any given category instance was found to be strongly related to its representativeness in the relevant category. Although "representative" can be defined in several ways, the property that was observed to be most important to creative generation was retrievability or "coming-to-mindedness"- that is, how readily an instance comes to mind when the category name is given as a cue. The more likely it is that a given item will come to mind when accessing a concept, the more likely it is that the item will be used as a starting point in developing a new idea. In the mechanical engineering domain, Jansson, Condoor, and Brock (1993) have made the related claim that design engineers tend to pattern new devices after readily accessible instances of earlier solutions, which often leads them to craft nonoptimal designs.

\section{Relation to Other Influences of Item Retrievability}

It may seem odd that people would have a tendency to rely on exemplars that come to mind quickly when they are engaged in a generative task, especially when they have been instructed to be creative. Might they not be expected to censor their own ideas to some extent and attempt to retrieve other, more exotic exemplars as models? Might they not produce more innovative creations if they assessed the appropriateness of the material that came to mind for the task at hand and rejected initial items in favor of later, more divergent ones? The tendency for the participants in the present creative generation tasks to stick with the prosaic items that came to mind quickly, rather than rejecting them in favor of something more exotic, is congruent with other observations of people not appropriately monitoring or excluding information that is readily available, though nonoptimal or incorrect.

First, there is the general phenomenon of people conforming to prior knowledge even when encouraged not to do so or when directly informed that it might interfere with their performance. This occurs for previously stored knowledge as well as for recently presented examples, for undergraduate students as well as for design engineers, and for a variety of domains, including toys, implements, animals, and faces (e.g., Bredart et al., 1998; Jansson \& Smith, 1991; Marsh et al., 1996; Smith et al., 1993; Ward \& Sifonis, 1997; Wiley, 1998). The picture that emerges is that either (1) people fail to assess whether a given piece of accessible information is legitimate or appropriate for the creative task they are performing or (2) having made the assessment, they nevertheless have difficulty avoiding the influence of that information. 
The fact that people conform to existing knowledge and to example-activated information despite instructions to avoid doing so suggests that at least a portion of the structured imagination phenomenon can be characterized as inadvertent in nature. To that extent, the phenomenon is also consistent with observations of inadvertent plagiarism in which participants copy instances they have been exposed to, despite admonitions not to do so (e.g., Brown \& Murphy, 1989; Marsh \& Bower, 1993; Marsh, Landau, \& Hicks, 1997). Of particular interest, Marsh et al. (1997) have shown that participants who plagiarize items to which they have been exposed are subsequently able to accurately identify the external origins of those items. Thus, in inadvertent plagiarism tasks as well, people do not effectively exclude inappropriate material that comes to mind, even though they may possess information that would allow them to do so.

A similar pattern emerges in studies of false or "created" memories. Smith, Ward, Tindell, Sifonis, and Wilkenfeld (2000) presented participants with categorized lists from which items at varying levels of output dominance and typicality had been deleted. Consistent with data from associatively structured lists (e.g., Deese, 1959; Roediger \& McDermott, 1995), participants falsely recalled some of the eliminated items. More importantly, participants were more likely to falsely recall those items that were higher in output dominance than those that were lower in output dominance. Interestingly, as in the present experiments, output dominance was a better predictor of performance than was typicality. When the variance that typicality shared with output dominance was controlled for, typicality was found to be uncorrelated with false recall. Thus, again, people seem not to be adept at excluding from the task items that may come to mind readily but are nevertheless inappropriate in that context. And, as in the case of unconscious plagiarism, participants do seem to have at least some types of source information that could help them to exclude such items but do not spontaneously make good use of that information (Smith, Tindell, Pierce, Gilliland, \& Gerkens, 2001).

One reason people may rely so heavily on items that come to mind easily is that generation tasks are cognitively demanding. Although the information is potentially available to allow people to reject inappropriate or limiting starting points, their cognitive resources are devoted elsewhere, leaving little left over to perform the needed metacognitive monitoring (see Marsh et al., 1997). Consistent with this view, participants in the no-appendages condition of Experiment 2B, who had the additional burden of figuring out how an appendageless creature could use a tool, showed no reduction in the likelihood of retrieving and using highly accessible instances of Earth tools, whereas those simply instructed to not be bound by Earth fruit but given no other constraints in Experiment 4 did show a reduction. The properties of the imaginary tools generated by the former participants suggest that they devoted resources to adapting tools to novel creatures rather than to moving away from readily accessible starting tools.
Despite the overwhelming influence of coming-tomindedness, the present findings also provide a hint that there may be some censoring of the items that come to mind, albeit in a very limited form. First, as noted earlier, instructions to not feel bound by Earth exemplars reduced reliance on those exemplars. Second, for both animals and tools, when controlling for the variance associated with retrievability, typicality was negatively correlated with use in imagination. Although highly speculative, it may be that people tend to rely on items that come to mind quickly, but, among those items that do so, they try to choose less typical instances. In a related way, Ward, Dodds, Saunders, and Sifonis (2000) showed that attributes that are equally likely to bring particular exemplars to mind can nevertheless have different effects on imagined entities. For example, arms and opposable thumbs are equally likely to bring humans to mind, but only the latter leads to an increase in the proportion of humanoid extraterrestrials that participants develop. Opposable thumbs are more central to the concept human than are arms, and the participants seem to have made use of centrality in determining the extent to which they would project the properties of humans onto their creations.

\section{The Human Effect and Flexible Category Construction}

An interesting exception to the general pattern of findings was that, in comparison with their near absence from lists of Earth animals, humans were overrepresented as sources of influence on the form of imagined extraterrestrials. One possible account of this unexpected finding is that category representations are flexible rather than rigid and that much of the graded structure of a category results from the way it is constructed on a given occasion or in a particular context. Ratings of typicality, for instance, have been shown to vary with a number of factors, including the perspective the respondent is supposed to adopt (Barsalou, 1987) and the specific concepts that are merged in a combination (e.g., Medin \& Shoben, 1988). Likewise, gradations in retrievability can be expected to vary across situations. Thus, there may be something about the context of the generative task that leads to the category animal being constructed in such a way that human is more highly accessible than it is under ordinary listing conditions.

One important difference between the listing and imagination tasks, for instance, is that they involve different implicit contrasts. In the Earth animal listing task, the focus is necessarily on creatures that live on Earth, exclusively. In that context, the term animal may embody a natural contrast between humans and other animals, with the consequence that humans are unlikely to come to mind as instances of the category animal. In the context of generating extraterrestrials, however, the relevant contrast sets may no longer be humans versus animals, but rather living things on Earth versus those not on Earth. In that context, humans would become part of the set of possible Earth animal models and therefore more accessible in that task. Implicit or explicit contrast sets have been noted as sources 
of participants' tendencies to either list or fail to list certain category attributes (see, e.g., Tversky \& Hemenway, 1984), and it is reasonable to suppose that a similar phenomenon influences the accessibility and selection of category exemplars.

A number of other observations are also consistent with the idea that category construction is flexible in both noncreative and imaginative endeavors. For instance, priming from recent experiences may alter the typicality structure of the category that is constructed (e.g., Barsalou, 1987) and may make some items more accessible in the category (i.e., more likely to be listed as exemplars) than they ordinarily would be (e.g., Graf, Shimamura, \& Squire, 1985). Similarly, in creative generation tasks, people's reliance on particular category instances has been shown to vary with the immediate context. For example, when participants are asked to imagine extraterrestrial animals, telling them that the creatures have attributes such as feathers and scales leads them to rely more on birds and fish than they do in control tasks (Ward, 1994). The result could reflect the fact that the attributes alter the structure of the concept as it is being constructed for use in imagination, such that birds and fish are more readily accessible than they ordinarily would be. Likewise, we would expect that instructional conditions that increased the accessibility of particular tools or fruit would lead to a greater use of those items in an imagination task. For instance, a planet with lots of wood might increase the accessibility of carpentry tools and thus lead to more use of those tools in generating ideas for imaginary tools.

Conceptualized in this way, data from creative tasks are again seen to be consistent with those from false memory tasks. Smith et al. (2000), for instance, showed that priming by way of a pleasantness rating task increases the likelihood of a given exemplar being falsely recalled. Presumably, the priming alters the accessibility of the items, such that participants confuse them with actual list items.

An alternative account of the human effect is that it reflects something about the underlying structure of the animal category and how it is projected in imagination. Participants may be exhibiting a kind of humanocentric bias in that their concepts of animals may be organized around and derive at least some of their meaning from their relation to humans. When faced with the task of creating novel animals, participants may have a strong tendency to project much of this central aspect of themselves - that is, their humanness-onto the new entities.

\section{Variations in Category Structures and Expansion Mechanisms}

Although general in the sense of operating across different conceptual domains and conditions, the present results are limited in the sense that the data come from North American adults (i.e., college students). The strongest case of the path of least resistance is that it involves a universal tendency to gravitate toward items that come to mind readily. Thus, in future research, it will be important to examine not only a broader range of conceptual domains but also a broader range of participants. Any cultural, linguis- tic, or developmental differences in the retrievability of specific category instances ought to be reflected in differential reliance on those instances in tasks of imagination.

Conceptual expansion can also occur through a variety of other mechanisms, including the combination of previously separate concepts (Hampton, 1987, 1997; Murphy, 1988; Thagard, 1997; Wisniewski, 1996, 1997), the metaphoric representation of one domain in terms of another (Glucksberg \& Keysar, 1990; Glucksberg, Manfredi, \& McGlone, 1997; Tourangeau \& Rips, 1991), and the analogical transfer of knowledge from one domain to another (Gentner, 1983, 1989; Holyoak \& Thagard, 1989, 1995). Factors, such as "coming-to-mindedness," that are found to be important for one aspect of conceptual expansion are good candidates for playing a role in other aspects. In conceptual combination, for instance, potential interpretations that come to mind most readily, perhaps on the basis of the prior combinatorial histories of their components (e.g., Gagne \& Shoben, 1997), may be adopted even if they are not necessarily optimal in a given situation. Shifting to more creatively appropriate interpretations may require additional cognitive resources (see, e.g., Hampton, 1997). Likewise, source analogs that are readily accessible may dominate responding, even if they do not provide the best analogies according to structural alignment principles (e.g., Gentner, 1983; Gentner \& Toupin, 1986). The most successful uses of analogies may involve the continued assessment and refinement of the links between sources and targets (see, e.g., Gentner et al., 1997). Thus, part of being creative may be in the capacity or willingness to move beyond initially retrieved information to better or more refined exemplars, interpretations, and source analogs. Research on creative cognition holds the promise of identifying the most effective means of facilitating such efforts.

\section{REFERENCES}

BARSALOU, L. W. (1985). Ideals, central tendency, and frequency of instantiation. Journal of Experimental Psychology: Learning, Memory, \& Cognition, 11, 629-654.

BARSAlOU, L. W. (1987). The instability of graded structure: Implications for the nature of concepts. In U. Neisser (Ed.), Concepts and conceptual development: Ecological and intellectual factors in categorization (pp. 101-140). Cambridge: Cambridge University Press.

Basalla, G. (1988). The evolution of technology. London: Cambridge University Press.

Battig, W. F., \& Montague, W. E. (1969). Category norms for verbal items in 56 categories: A replication and extension of the Connecticut category norms. Journal of Experimental Psychology Monographs, 80(3, Pt 2).

Bredart, S., Ward, T. B., \& Marczewski, P. (1998). Structured imagination of novel creatures' faces. American Journal of Psychology, 111, 607-625.

Brown, A. S., \& Murphy, D. R. (1989). Cryptomnesia: Delineating inadvertent plagiarism. Journal of Experimental Psychology: Learning, Memory, \& Cognition, 15, 432-442.

Cacciari, C., Levorato, M. C., \& Cicogna, P. (1997). Imagination at work: Conceptual and linguistic creativity in children. In T. B. Ward, S. M. Smith, \& J. Vaid (Eds.), Creative thought: An investigation of conceptual structures and processes (pp. 145-177). Washington, DC: American Psychological Association.

Condoor, S. S., Brock, H. R., \& Burger, C. P. (1993, June). Innovation throughearly recognition of critical design parameters. Paper pre- 
sented at the meeting of the American Society for Engineering Education, Urbana, IL.

DEESE, J. (1959). On the prediction of occurrence of particular verbal intrusions in immediate recall. Journal of Experimental Psychology, 58, 17-22.

Gagne, C. L., \& Shoben, E. J. (1997). The influence of thematic relations on the comprehension of nonpredicating combinations. Journal of Experimental Psychology: Learning, Memory, \& Cognition, 23, 71-87.

Gentner, D. (1983). Structure mapping: A theoretical framework for analogy. Cognitive Science, 7, 155-170.

GENTNER, D. (1989). The mechanisms of analogical learning. In S. Vosniadou \& A. Ortony (Eds.), Similarity and analogical reasoning (pp. 199-241). Cambridge: Cambridge University Press.

Gentner, D., Brem, S., Ferguson, R., Wolff, P., Markman, A. B., \& Forbus, K. (1997). Analogy and creativity in the works of Johannes Kepler. In T. B. Ward, S. M. Smith, \& J. Vaid (Eds.), Creative thought: An investigation of conceptual structures and processes (pp. 403460). Washington, DC: American Psychological Association.

Gentner, D., \& Toupin, C. (1986). Systematicity and surface similarity in the development of analogy. Cognitive Science, 10, 277-300.

Glucksberg, S., \& Keysar, B. (1990). Understanding metaphorical comparisons: Beyond similarity. Psychological Review, 97, 3-18.

Glucksberg, S., Manfredi, D. A., \& McGlone, M. S. (1997). Metaphor comprehension: How metaphors create new categories. In T. B. Ward, S. M. Smith, \& J. Vaid (Eds.), Creative thought: An investigation of conceptual structures and processes (pp. 327-350). Washington, DC: American Psychological Association.

Graf, P., Shimamura, A. P., \& Seuire, L. R. (1985). Priming across modalities and priming across category levels: Extending the domain of preserved function in amnesia. Journal of Experimental Psychology: Learning, Memory, \& Cognition, 11, 386-396.

HAMPTON, J. A. (1987). Inheritance of attributes in natural concept conjunctions. Memory \& Cognition, 15, 55-71.

HAMPTON, J. A. (1997). Emergent attributes in combined concepts. In T. B. Ward, S. M. Smith, \& J. Vaid (Eds.), Creative thought: An investigation of conceptual structures and processes (pp. 83-110). Washington, DC: American Psychological Association.

Holyoak, K. J., \& ThagaRd, P. R. (1989). A computational model of analogical problem solving. In S. Vosniadou \& A. Ortony (Eds.), Similarity and analogical reasoning (pp. 242-266). New York: Cambridge University Press.

Holyoak, K. J., \& Thagard, P. R. (1995). Mental leaps. Cambridge, MA: MIT Press.

Jansson, D. G., Condoor, S. S., \& Brock, H. R. (1993). Cognition in design: Viewing the hidden side of the design process. Environment \& Planning-B, Planning \& Design, 20, 257-271.

Jansson, D. G., \& SMith, S. M. (1991). Design fixation. Design Studies, 12, 3-11.

KARMILOFF-SMith, A. (1990). Constraints on representational change: Evidence from children's drawing. Cognition, 34, 57-83.

MARSH, R. L., \& Bower, G. H. (1993). Eliciting cryptomnesia: Unconscious plagiarism in a puzzle task. Journal of Experimental Psychology: Learning, Memory, \& Cognition, 19, 673-688.

Marsh, R. L., LANDAU, J. D., \& Hicks, J. L. (1996). How examples may (and may not) constrain creativity. Memory \& Cognition, 24, 669-680.

Marsh, R. L., LandaU, J. D., \& Hicks, J. L. (1997). Contributions of inadequate source monitoring to unconscious plagiarism during idea generation. Journal of Experimental Psychology: Learning, Memory, \& Cognition, 23, 886-897.

Marsh, R. L., Ward, T. B., \& LANDAU, J. D. (1999). The inadvertent use of prior knowledge in a generative cognitive task. Memory \& Cognition, 27, 94-105.

Medin, D. L., \& Shoben, E. J. (1988). Context and structure in conceptual combination. Cognitive Psychology, 20, 158-190.

Murphy, G. L. (1988). Comprehending complex concepts. Cognitive Science, 12, 529-562.

Perkins, D. N. (1981). The mind's best work. Cambridge, MA: Harvard University Press.

Perkins, D. N. (1988). Creativity and the quest for a mechanism. In R. J. Sternberg \& E. E. Smith (Eds.), The psychology of human thought (pp. 309-336). New York: Cambridge University Press.

Roediger, H. L., III, \& McDermott, K. B. (1995). Creating false mem- ories: Remembering words not presented in lists. Journal of Experimental Psychology: Learning, Memory, \& Cognition, 21, 803-814.

Rubin, D. C., \& Kontis, T. C. (1983). A schema for common cents. Memory \& Cognition, 11, 335-341.

Schank, R. C., \& Cleary, C. (1995). Making machines creative. In S. M. Smith, T. B. Ward, \& R. A. Finke (Eds.), The creative cognition approach (pp. 229-248). Cambridge, MA: MIT Press.

SIFONIS, C. M. (1995). Scene schemas and creativity: Examining the influence of schema based knowledge on the creative process. Unpublished master's thesis, Texas A\&M University.

Sifonis, C. M., Ward, T. B., Gentner, D., \& Houska, M. (1997). Relation versus object mapping in creative generation. Proceedings of the Nineteenth Annual Conference of the Cognitive Science Society, 19, 1050.

Smith, S. M., Tindell, D. R., Pierce, B. H., Gilliland, T. R., \& Gerkens, D. R. (2001). The use of source memory to identify one's own episodic confusion errors. Journal of Experimental Psychology: Learning, Memory, \& Cognition, 27, 362-374.

Smith, S. M., Ward, T. B., \& Schumacher, J. S. (1993). Constraining effects of examples in a creative generation task. Memory \& Cognition, 21, 837-845.

Smith, S. M., Ward, T. B., Tindell, D. R., Sifonis, C. M., \& WilkenFELD, M. J. (2000). Category structure and created memories. Memory \& Cognition, 28, 386-395.

Thagard, P. (1997). Coherent and creative conceptual combinations. In T. B. Ward, S. M. Smith, \& J. Vaid (Eds.), Creative thought: An investigation of conceptual structures and processes (pp. 129-141). Washington, DC: American Psychological Association.

Tourangeau, R., \& RiPS, L. (1991). Interpreting and evaluating metaphors. Journal of Memory \& Language, 30, 452-472.

TVERSKY, B., \& HeMENWAY, K. (1984). Objects, parts, and categories. Journal of Experimental Psychology: General, 113, 169-193.

WARD, T. B. (1994). Structured imagination: The role of conceptual structure in exemplar generation. Cognitive Psychology, 27, 1-40.

WARD, T. B. (1995). What's old about new ideas? In S. M. Smith, T. B. Ward, \& R. A. Finke (Eds.), The creative cognition approach (pp. 157-178). Cambridge, MA: MIT Press.

Ward, T. B., Dodds, R. A., Saunders, K. N., \& Sifonis, C. M. (2000). Attribute centrality and imaginative thought. Memory \& Cognition, 28, 1387-1397.

WARD, T. B., Finke, R. A., \& SMith, S. M. (1995). Creativity and the mind: Discovering the genius within. New York: Plenum.

WARd, T. B., SAunders, K. N., \& DodDS, R. A. (1999). Creative cognition in gifted adolescents. Roeper Review, 21, 260-265.

WARD, T. B., \& Sifonis, C. M. (1997). Task demands and generative thinking: What changes and what remains the same? Journal of Creative Behavior, 31, 245-259.

WARD, T. B., SMITH, S. M., \& VAID, J. (1997). Conceptual structures and processes in creative thought. In T. B. Ward, S. M. Smith, \& J. Vaid (Eds.), Creative thought: An investigation of conceptual structures and processes (pp. 1-27). Washington, DC: American Psychological Association.

WeISBERG, R. W. (1986). Creativity, genius and other myths. New York: Freeman.

WeISBERG, R. W. (1993). Creativity: Beyond the myth of genius. New York: Freeman.

WiLEY, J. (1998). Expertise as mental set: The effects of domain knowledge in creative problem solving. Memory \& Cognition, 26, 716-730.

WISNIEWSKI, E. J. (1996). Construal and similarity in conceptual combination. Journal of Memory \& Language, 35, 434-453.

WISNIEWSKI, E. J. (1997). Conceptual combination: Possibilities and esthetics. In T. B. Ward, S. M. Smith, \& J. Vaid (Eds.), Creative thought: An investigation of conceptual structures and processes (pp. 51-81). Washington, DC: American Psychological Association.

\section{NOTES}

1. These data are also available on line at http://creativityforyou.com/ genlab.html.

2. Not surprisingly, the participants gave extremely high ratings to human on the scales of familiarity, liking, similarity to humans, and centrality to human concerns. Thus, it is conceivable that humans are cho- 
sen frequently as models for imaginary creatures because participants are highly familiar with humans, because they like humans more than most other species, and so on. However, because humans are also high in imagination frequency, high ratings for humans on those rating scales could artificially magnify the correlations between those ratings and imagination frequency, even if the relationships are not particularly strong for the remaining set of nonhuman animals. Put differently, even if those factors are responsible for the participants' relying on humans as models, this would not necessarily support the broader notion that they are also important in determining which among all other animals will be selected as models. Thus, it is important to examine the extent to which familiarity, perceived frequency, similarity to humans, and so on predict the likelihood of animals being used in imaginative tasks, excluding the influence of the exceptional case of humans.

APPENDIX A

Values of Output Dominance (OD), Rank, Dominance/Rank (OD/R), Output Precedence (OP), Imagination Frequency (IF), and Ratings of Liking, Typicality, Similarity, Familiarity, Frequency, and Centrality to Human Concerns for Animal Exemplars

\begin{tabular}{|c|c|c|c|c|c|c|c|c|c|c|c|}
\hline Animal & OD & Rank & $\mathrm{OD} / \mathrm{R}$ & $\mathrm{OP}$ & IF & Liking & Typicality & Similarity & Familiarity & Frequency & Centrality \\
\hline cat & 28 & 2.89 & 9.69 & 507 & 4 & 4.5 & 5.5 & 3.06 & 6.69 & 6.56 & 5.31 \\
\hline $\operatorname{dog}$ & 27 & 2.37 & 11.39 & 503 & 8 & 6.81 & 5.94 & 4.63 & 6.88 & 6.69 & 6.19 \\
\hline lion & 21 & 9.81 & 2.14 & 235 & 1 & 5.44 & 6.81 & 3.31 & 5.13 & 3.88 & 4.25 \\
\hline horse & 21 & 7.42 & 2.83 & 285 & 2 & 6.31 & 6.06 & 3.13 & 6.38 & 6.25 & 6.75 \\
\hline tiger & 20 & 10.3 & 1.94 & 214 & 3 & 5.88 & 6.63 & 3.69 & 5.19 & 4 & 3.81 \\
\hline bird & 20 & 9.15 & 2.19 & 237 & 3 & 5.06 & 4.44 & 2 & 6.38 & 6.88 & 5.69 \\
\hline cow & 18 & 11.61 & 1.55 & 169 & 1 & 4.88 & 5.38 & 3 & 6.31 & 6.5 & 6.88 \\
\hline elephant & 17 & 10 & 1.7 & 187 & 6 & 5.69 & 6.56 & 2.81 & 5.44 & 4.19 & 4.5 \\
\hline pig & 16 & 11.06 & 1.45 & 159 & 2 & 4.44 & 5 & 2.81 & 5.25 & 5.63 & 6 \\
\hline bear & 15 & 13.27 & 1.13 & 116 & 2 & 5.13 & 6.38 & 4.06 & 5.44 & 4.69 & 4.06 \\
\hline monkey & 15 & 11.4 & 1.32 & 144 & 2 & 5.31 & 6.25 & 6.19 & 5.38 & 5.19 & 5.38 \\
\hline fish & 15 & 10.47 & 1.43 & 158 & 1 & 4.44 & 4.75 & 1.88 & 6.31 & 6.75 & 6.38 \\
\hline snake & 15 & 10.13 & 1.48 & 163 & 1 & 3.69 & 4.69 & 2 & 5.94 & 6.31 & 3.06 \\
\hline mouse & 14 & 9.43 & 1.49 & 162 & 0 & 3.13 & 4.06 & 1.81 & 5.13 & 5.94 & 4.06 \\
\hline giraffe & 14 & 8.5 & 1.65 & 175 & 0 & 5.06 & 6.06 & 2.63 & 4.94 & 3.75 & 3.63 \\
\hline rat & 12 & 11.42 & 1.05 & 115 & 2 & 2.44 & 3.81 & 1.69 & 5.38 & 6.13 & 4.19 \\
\hline zebra & 12 & 9.67 & 1.24 & 136 & 0 & 5.19 & 5.94 & 2.94 & 4.63 & 3.75 & 3.38 \\
\hline deer & 10 & 10.5 & 0.95 & 105 & 0 & 5.75 & 5.75 & 3.5 & 5.94 & 5.06 & 5.56 \\
\hline rabbit & 10 & 9.4 & 1.06 & 116 & 5 & 5.19 & 4.69 & 2.69 & 5.88 & 6.13 & 4.88 \\
\hline chicken & 9 & 13 & 0.69 & 72 & 1 & 4.19 & 4.06 & 2.56 & 6.06 & 6.13 & 6.56 \\
\hline squirrel & 9 & 12.78 & 0.7 & 74 & 0 & 5.44 & 5.19 & 3 & 5.56 & 5.75 & 4.56 \\
\hline whale & 9 & 12.44 & 0.72 & 77 & 0 & 5.25 & 5.63 & 3.44 & 4.88 & 3.5 & 4.63 \\
\hline alligator & 7 & 13.28 & 0.53 & 54 & 0 & 3.88 & 5.63 & 1.94 & 5.13 & 3.88 & 3.63 \\
\hline ostrich & 7 & 10 & 0.7 & 77 & 0 & 4.31 & 5.5 & 2.19 & 3.88 & 3.75 & 3.94 \\
\hline rhino & 7 & 8.85 & 0.79 & 85 & 0 & 4.56 & 6.31 & 2.5 & 4 & 2.94 & 3.06 \\
\hline armadillo & 5 & 17.2 & 0.29 & 19 & 0 & 4.38 & 5 & 2.25 & 4.5 & 4.38 & 2.88 \\
\hline dolphin & 5 & 14.4 & 0.35 & 33 & 0 & 6.25 & 5.31 & 3.69 & 5.13 & 4.06 & 5.38 \\
\hline buffalo & 5 & 12.4 & 0.4 & 43 & 0 & 4.75 & 6.06 & 2.75 & 4.25 & 3.06 & 4.5 \\
\hline goat & 5 & 12 & 0.42 & 45 & 0 & 3.88 & 5.25 & 2.81 & 4.56 & 4.69 & 5.19 \\
\hline kangaroo & 5 & 11.2 & 0.45 & 49 & 0 & 5.38 & 6.25 & 3.75 & 4.75 & 3.5 & 4.13 \\
\hline moose & 5 & 9.8 & 0.51 & 56 & 0 & 4.19 & 6.25 & 3 & 3.81 & 3.31 & 3.81 \\
\hline wolf & 5 & 7.2 & 0.69 & 69 & 1 & 4.88 & 6.63 & 3.19 & 4.75 & 4.63 & 4.25 \\
\hline flamingo & 4 & 14.5 & 0.28 & 26 & 1 & 4.75 & 4.81 & 2.19 & 3.69 & 3.69 & 3 \\
\hline llama & 4 & 13.5 & 0.3 & 30 & 0 & 4.19 & 5.56 & 2.5 & 3.19 & 3.31 & 3.56 \\
\hline coyote & 4 & 13.25 & 0.3 & 31 & 0 & 3.94 & 5.88 & 3.31 & 4.31 & 4.38 & 3.06 \\
\hline hippo & 4 & 11 & 0.36 & 40 & 0 & 4.69 & 6.06 & 2.69 & 4.44 & 3.5 & 3.56 \\
\hline duck & 4 & 11 & 0.36 & 40 & 0 & 4.56 & 4.69 & 1.88 & 5.44 & 5.81 & 4.81 \\
\hline turkey & 4 & 10.75 & 0.37 & 41 & 0 & 3.5 & 4.88 & 2.19 & 5.31 & 5.19 & 5.5 \\
\hline turtle & 4 & 10.75 & 0.37 & 41 & 2 & 5.06 & 4.75 & 2.25 & 6 & 5.19 & 4.19 \\
\hline antelope & 4 & 10 & 0.4 & 44 & 0 & 4.25 & 5.88 & 2.81 & 3.25 & 3.63 & 4.19 \\
\hline cheetah & 4 & 9.75 & 0.41 & 45 & 0 & 5.88 & 6.31 & 3.75 & 4.88 & 3.69 & 3.69 \\
\hline frog & 4 & 8.75 & 0.46 & 49 & 0 & 4.19 & 4.38 & 1.81 & 5.88 & 6.06 & 4.25 \\
\hline fox & 4 & 8.25 & 0.49 & 51 & 2 & 5 & 5.94 & 3.5 & 4.5 & 4.94 & 3.56 \\
\hline skunk & 3 & 17.33 & 0.17 & 11 & 0 & 2.88 & 5.31 & 2.69 & 5.19 & 4.94 & 2.88 \\
\hline penguin & 3 & 16.67 & 0.18 & 13 & 0 & 5.44 & 4.94 & 2.88 & 4.19 & 3.31 & 3.44 \\
\hline leopard & 3 & 14.67 & 0.2 & 19 & 0 & 5.56 & 6.75 & 3.69 & 4.5 & 3.75 & 3.69 \\
\hline mosquito & 3 & 14 & 0.21 & 21 & 0 & 1.31 & 2.69 & 1.81 & 6.13 & 6.25 & 2.25 \\
\hline shark & 3 & 14 & 0.21 & 21 & 0 & 4.13 & 5.38 & 2.44 & 4.63 & 4 & 3.56 \\
\hline polar bear & 3 & 13.33 & 0.23 & 23 & 0 & 5.94 & 6.56 & 3.88 & 4.38 & 3.19 & 3.69 \\
\hline panda & 3 & 13.33 & 0.23 & 23 & 0 & 5.75 & 5.94 & 3.38 & 4.13 & 2.69 & 3.94 \\
\hline seal & 3 & 12.67 & 0.24 & 25 & 0 & 5.81 & 5.75 & 2.81 & 4.31 & 3.5 & 3.75 \\
\hline ape & 3 & 12 & 0.25 & 27 & 0 & 4.94 & 6.31 & 6.19 & 4.75 & 4.25 & 5.25 \\
\hline parrot & 3 & 11 & 0.27 & 30 & 0 & 4.94 & 4.44 & 3.25 & 5 & 4.38 & 3.63 \\
\hline elk & 3 & 11 & 0.27 & 30 & 0 & 3.63 & 5.31 & 2.63 & 3.63 & 3.81 & 4.38 \\
\hline gerbil & 3 & 10.33 & 0.29 & 32 & 0 & 4.44 & 3.94 & 1.88 & 5 & 5.19 & 3.81 \\
\hline
\end{tabular}


APPENDIX A (Continued)

\begin{tabular}{|c|c|c|c|c|c|c|c|c|c|c|c|}
\hline Animal & OD & Rank & $\mathrm{OD} / \mathrm{R}$ & $\mathrm{OP}$ & IF & Liking & Typicality & Similarity & Familiarity & Frequency & Centrality \\
\hline gorilla & 3 & 9.67 & 0.31 & 34 & 0 & 5 & 6.5 & 6 & 4.69 & 3.69 & 5.06 \\
\hline swan & 3 & 8.67 & 0.35 & 37 & 0 & 5.13 & 4.63 & 2.25 & 4.06 & 3.88 & 3.38 \\
\hline donkey & 3 & 8 & 0.38 & 39 & 0 & 3.94 & 5.38 & 3.13 & 4.94 & 4.75 & 4.56 \\
\hline chimp & 2 & 11 & 0.18 & 20 & 1 & 5.44 & 6.19 & 5.81 & 4.94 & 4.5 & 5.69 \\
\hline human & 1 & 20 & 0.05 & 1 & 12 & 6.44 & 4.56 & 7 & 7 & 6.81 & 6.63 \\
\hline snail & 1 & 20 & 0.05 & 1 & 1 & 2.75 & 2.88 & 1.56 & 5.13 & 5.19 & 2.13 \\
\hline jellyfish & 1 & 19 & 0.05 & 2 & 2 & 2.44 & 3.63 & 1.5 & 4.81 & 4.69 & 2 \\
\hline roach & 1 & 18 & 0.06 & 3 & 1 & 1.44 & 2.25 & 1.13 & 6.06 & 6.31 & 1.63 \\
\hline praying mantis & 1 & 18 & 0.06 & 3 & 1 & 2.94 & 3.13 & 1.63 & 3.69 & 3.75 & 2.5 \\
\hline grasshopper & 1 & 16 & 0.06 & 5 & 1 & 3.06 & 2.94 & 1.5 & 5.38 & 5.88 & 2.94 \\
\hline dinosaur & 1 & 15 & 0.07 & 6 & 2 & 4.31 & 4.63 & 2.38 & 4.38 & 1.5 & 3.94 \\
\hline ferret & 1 & 11 & 0.09 & 10 & 1 & 5.25 & 4.94 & 2.38 & 3.94 & 4.19 & 3.75 \\
\hline pterodactyl & 0 & & 0 & 0 & 1 & 3.31 & 4.19 & 1.25 & 3.06 & 1.06 & 3.44 \\
\hline slug & 0 & & 0 & 0 & 2 & 2 & 2.31 & 1.38 & 4.75 & 4.63 & 1.94 \\
\hline goldfish & 0 & & 0 & 0 & 1 & 4.19 & 4 & 1.63 & 6.38 & 5.88 & 3.63 \\
\hline
\end{tabular}

APPENDIX B

Values of Output Dominance (OD), Rank, Dominance/Rank (OD/R), Output Precedence (OP), and Imagination Frequency in the Control Condition (IF Con), Imagination Frequency in the No-Appendages Condition (IF NA), Total Imagination Frequency (IF Total), and Ratings of Frequency, Typicality, Familiarity, and Usefulness for Tool Exemplars

\begin{tabular}{|c|c|c|c|c|c|c|c|c|c|c|c|}
\hline Tool & OD & Rank & $\mathrm{OD} / \mathrm{R}$ & $\mathrm{OP}$ & IF Con & IF NA & IF Total & Frequency & Typicality & Familiarity & Usefulness \\
\hline hammer & 29 & 1.86 & 15.57 & 555 & 12 & 11 & 23 & 5.6 & 6.75 & 6.8 & 5.95 \\
\hline screwdriver & 25 & 5.24 & 4.77 & 394 & 1 & 5 & 6 & 5.5 & 6.7 & 6.7 & 5.5 \\
\hline wrench & 24 & 5.17 & 4.65 & 380 & 2 & 1 & 3 & 5 & 6.6 & 6.1 & 4.75 \\
\hline saw & 20 & 5.85 & 3.42 & 303 & 0 & 3 & 3 & 4.45 & 6.4 & 6.55 & 5.1 \\
\hline nails & 16 & 4.63 & 3.46 & 262 & 1 & 1 & 2 & 5.55 & 5.05 & 6.55 & 5.45 \\
\hline pliers & 16 & 9.31 & 1.72 & 187 & 1 & 1 & 2 & 4.95 & 6.6 & 6.05 & 5.2 \\
\hline drill & 12 & 8.58 & 1.4 & 149 & 0 & 0 & 0 & 4.6 & 6.5 & 5.8 & 5.05 \\
\hline knife & 11 & 11 & 1 & 110 & 5 & 6 & 11 & 6.55 & 5.45 & 6.9 & 6.4 \\
\hline pencil & 9 & 11.11 & 0.81 & 89 & 3 & 2 & 5 & 6.6 & 4.25 & 7 & 6.35 \\
\hline screws & 9 & 9.33 & 0.96 & 105 & 0 & 0 & 0 & 5.5 & 4.75 & 6.45 & 5.55 \\
\hline \multicolumn{12}{|l|}{ monkey } \\
\hline wrench & 7 & 8.57 & 0.82 & 87 & 0 & 0 & 0 & 3.65 & 6.55 & 4.45 & 4.35 \\
\hline sander & 7 & 10.14 & 0.69 & 76 & 0 & 0 & 0 & 3.25 & 6.2 & 5.2 & 4.2 \\
\hline scissors & 7 & 9.71 & 0.72 & 79 & 0 & 1 & 1 & 5.8 & 5.35 & 6.85 & 5.65 \\
\hline sledgehammer & 7 & 11.71 & 0.6 & 65 & 0 & 0 & 0 & 3.55 & 5.95 & 5.55 & 4.1 \\
\hline axe & 6 & 10.33 & 0.58 & 64 & 3 & 1 & 4 & 4.35 & 6.45 & 5.65 & 4.35 \\
\hline level & 6 & 11.33 & 0.53 & 58 & 0 & 0 & 0 & 4.15 & 5.4 & 5.35 & 4.25 \\
\hline pen & 6 & 12.83 & 0.47 & 49 & 0 & 0 & 0 & 6.6 & 4.45 & 6.95 & 6.5 \\
\hline \multicolumn{12}{|l|}{ Phillips } \\
\hline screwdriver & 6 & 7.5 & 0.8 & 81 & 0 & 0 & 0 & 5.05 & 6.5 & 6.65 & 5.6 \\
\hline ruler & 6 & 13.17 & 0.46 & 47 & 2 & 0 & 2 & 5.85 & 5.15 & 6.85 & 6.05 \\
\hline wire cutters & 6 & 11.5 & 0.52 & 57 & 0 & 0 & 0 & 4.5 & 6.3 & 5.8 & 4.5 \\
\hline chainsaw & 5 & 6.8 & 0.74 & 71 & 0 & 0 & 0 & 3.9 & 6.35 & 4.7 & 4.55 \\
\hline crowbar & 5 & 10 & 0.5 & 55 & 1 & 0 & 1 & 4.05 & 6.05 & 5.35 & 4.5 \\
\hline \multicolumn{12}{|l|}{ flathead } \\
\hline screwdriver & 5 & 6.6 & 0.76 & 72 & 0 & 0 & 0 & 4.95 & 6.55 & 6.45 & 5.5 \\
\hline jigsaw & 5 & 10.2 & 0.49 & 54 & 0 & 0 & 0 & 4.25 & 5.2 & 4.85 & 4.2 \\
\hline shovel & 5 & 10.8 & 0.46 & 51 & 8 & 6 & 14 & 5.3 & 5.95 & 6.9 & 5.4 \\
\hline staple gun & 5 & 14 & 0.36 & 35 & 0 & 0 & 0 & 4.3 & 5.75 & 5.9 & 4.45 \\
\hline bolt & 4 & 11 & 0.36 & 40 & 0 & 0 & 0 & 5 & 4.65 & 6.15 & 5.7 \\
\hline chisel & 4 & 6.75 & 0.59 & 57 & 0 & 0 & 0 & 4.35 & 6.15 & 5.4 & 4.2 \\
\hline clamps & 4 & 12.25 & 0.33 & 35 & 0 & 0 & 0 & 4.2 & 5.95 & 5.25 & 4.45 \\
\hline fork & 4 & 9.75 & 0.41 & 45 & 0 & 2 & 2 & 6.5 & 4.2 & 6.85 & 6.1 \\
\hline jackhammer & 4 & 10.75 & 0.37 & 41 & 0 & 0 & 0 & 3.1 & 6.5 & 3.45 & 3.7 \\
\hline mallet & 4 & 10 & 0.4 & 44 & 0 & 0 & 0 & 4.6 & 5.85 & 5.15 & 4.15 \\
\hline socket set & 4 & 9.5 & 0.42 & 46 & 0 & 0 & 0 & 3.9 & 5.8 & 5.4 & 4.75 \\
\hline spoon & 4 & 14.25 & 0.28 & 27 & 0 & 1 & 1 & 6.65 & 4.45 & 7 & 5.9 \\
\hline tape measure & 4 & 12.5 & 0.32 & 34 & 0 & 0 & 0 & 4.6 & 6.25 & 6.6 & 5.4 \\
\hline allen wrench & 3 & 9.67 & 0.31 & 34 & 0 & 0 & 0 & 3.4 & 6.25 & 4.1 & 4.15 \\
\hline bandsaw & 3 & 9 & 0.33 & 36 & 0 & 0 & 0 & 3.1 & 5.9 & 3.5 & 3.95 \\
\hline crescent wrench & 3 & 7.33 & 0.41 & 41 & 0 & 0 & 0 & 3.45 & 6.3 & 4.95 & 4.55 \\
\hline gluegun & 3 & 18.67 & 0.16 & 7 & 0 & 0 & 0 & 4.15 & 5.4 & 6.1 & 3.85 \\
\hline
\end{tabular}


APPENDIX B (Continued)

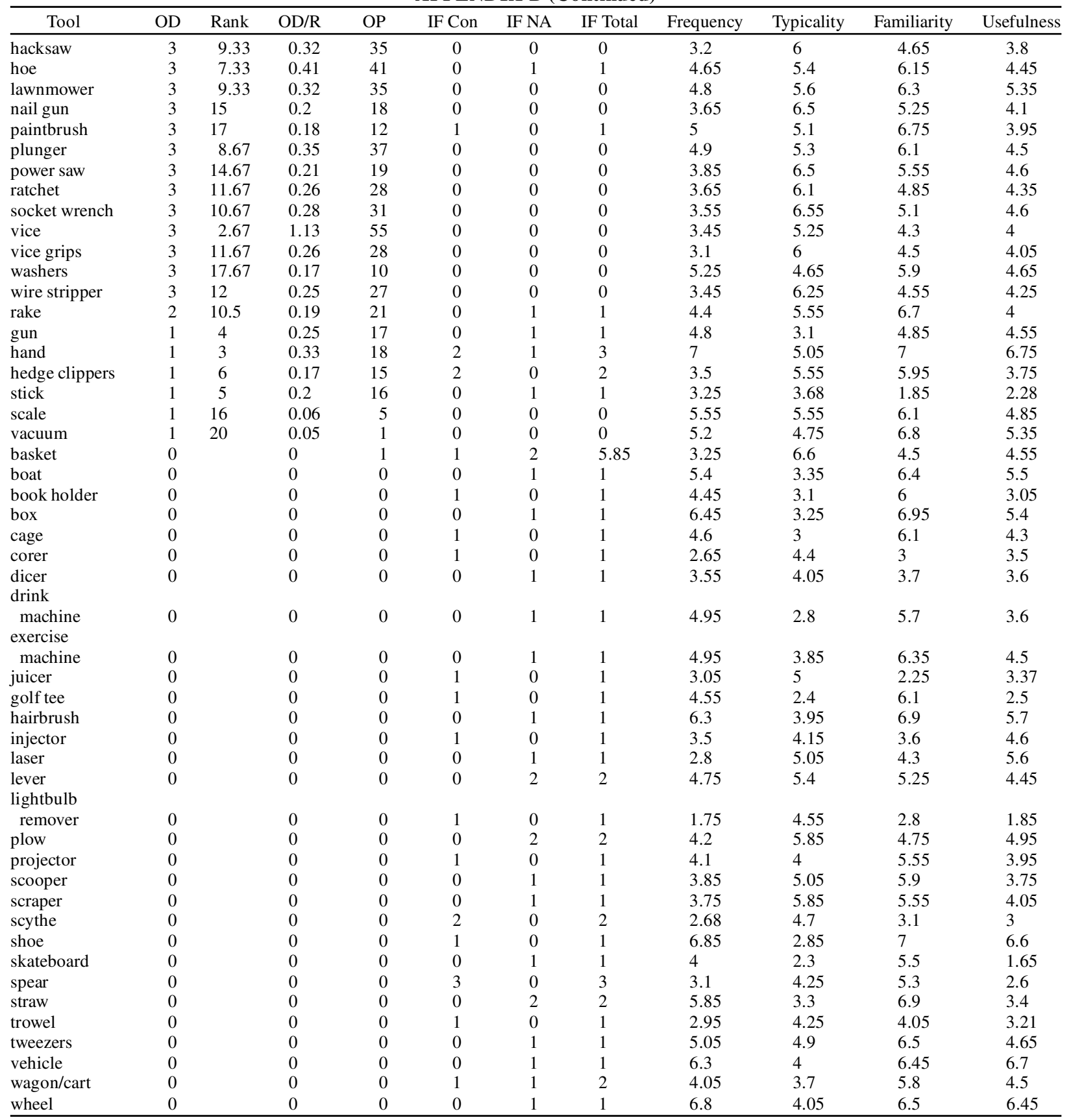


APPENDIX C

Values of Output Dominance (OD), Rank, Dominance/Rank (OD/R), Output Precedence (OP), and Imagination Frequency in the Control Condition (IF Con), Imagination Frequency in the Creative Condition (IF Creat), Imagination Frequency in the Not-Bound Condition (IF NB), and Total Imagination Frequency (IF Total) for Fruit Exemplars

\begin{tabular}{|c|c|c|c|c|c|c|c|c|}
\hline Fruit & OD & Rank & OD/R & $\mathrm{OP}$ & IF Con & IF Creat & IF NB & IF Total \\
\hline orange & 35 & 3.4 & 10.29 & 616 & 17 & 5 & 12 & 34 \\
\hline apple & 34 & 2.44 & 13.93 & 631 & 27 & 6 & 2 & 35 \\
\hline banana & 34 & 6.03 & 5.64 & 509 & 7 & 5 & 7 & 19 \\
\hline strawberry & 33 & 6.73 & 4.91 & 471 & 8 & 4 & 6 & 18 \\
\hline grape & 31 & 6.58 & 4.71 & 447 & 3 & 1 & 3 & 7 \\
\hline watermelon & 31 & 10.19 & 3.04 & 335 & 4 & 3 & 1 & 8 \\
\hline kiwi & 30 & 8.23 & 3.64 & 383 & 7 & 3 & 2 & 12 \\
\hline peach & 29 & 10.45 & 2.78 & 306 & 6 & 2 & 2 & 10 \\
\hline pear & 29 & 9.48 & 3.06 & 334 & 10 & 1 & 4 & 15 \\
\hline cantaloupe & 28 & 11.75 & 2.38 & 259 & 1 & 0 & 0 & 1 \\
\hline blueberry & 25 & 11 & 2.27 & 250 & 0 & 1 & 0 & 1 \\
\hline cherry & 22 & 10.32 & 2.13 & 235 & 2 & 1 & 0 & 3 \\
\hline lemon & 22 & 11.5 & 1.91 & 209 & 0 & 0 & 2 & 2 \\
\hline lime & 21 & 12.19 & 1.72 & 185 & 0 & 0 & 1 & 1 \\
\hline pineapple & 19 & 9.16 & 2.07 & 225 & 4 & 3 & 5 & 12 \\
\hline plum & 18 & 13.67 & 1.32 & 132 & 1 & 1 & 0 & 2 \\
\hline raspberry & 18 & 12.39 & 1.45 & 155 & 0 & 1 & 1 & 2 \\
\hline mango & 17 & 10.41 & 1.63 & 180 & 1 & 0 & 2 & 3 \\
\hline blackberry & 16 & 11.87 & 1.35 & 146 & 0 & 0 & 0 & 0 \\
\hline grapefruit & 16 & 10.25 & 1.56 & 172 & 3 & 0 & 2 & 5 \\
\hline honeydew melon & 15 & 15.53 & 0.97 & 82 & 1 & 0 & 0 & 1 \\
\hline tomato & 15 & 11.93 & 1.26 & 136 & 0 & 1 & 0 & 1 \\
\hline tangerine & 14 & 11.57 & 1.21 & 132 & 0 & 0 & 0 & 0 \\
\hline apricot & 13 & 12.69 & 1.02 & 108 & 1 & 0 & 0 & 1 \\
\hline nectarine & 12 & 14.17 & 0.85 & 82 & 0 & 0 & 0 & 0 \\
\hline cranberry & 11 & 16.27 & 0.68 & 52 & 0 & 0 & 0 & 0 \\
\hline coconut & 9 & 15 & 0.6 & 54 & 1 & 2 & 1 & 4 \\
\hline papaya & 7 & 12.14 & 0.58 & 62 & 0 & 1 & 0 & 1 \\
\hline melon & 5 & 14.2 & 0.35 & 34 & 1 & 1 & 0 & 2 \\
\hline green grape & 4 & 12 & 0.33 & 36 & 0 & 0 & 0 & 0 \\
\hline guava & 4 & 12 & 0.33 & 36 & 0 & 0 & 0 & 0 \\
\hline red apple & 4 & 10 & 0.4 & 44 & 0 & 0 & 0 & 0 \\
\hline red grape & 4 & 10.5 & 0.38 & 42 & 0 & 0 & 0 & 0 \\
\hline green apple & 3 & 6.34 & 0.47 & 44 & 0 & 0 & 0 & 0 \\
\hline purple grape & 3 & 15.34 & 0.2 & 17 & 0 & 0 & 0 & 0 \\
\hline boysenberry & 2 & 19 & 0.11 & 4 & 0 & 0 & 0 & 0 \\
\hline passionfruit & 2 & 11.5 & 0.17 & 19 & 0 & 0 & 0 & 0 \\
\hline raisin & 2 & 13.49 & 0.15 & 15 & 0 & 0 & 0 & 0 \\
\hline avocado & 1 & 16 & 0.06 & 5 & 2 & 1 & 0 & 3 \\
\hline black cherry & 1 & 14.02 & 0.07 & 7 & 0 & 0 & 0 & 0 \\
\hline cactus fruit & 1 & 18.98 & 0.05 & 2 & 0 & 0 & 0 & 0 \\
\hline carrot & 1 & 7 & 0.14 & 14 & 1 & 0 & 0 & 1 \\
\hline champagne grape & 1 & 19.99 & 0.05 & 1 & 0 & 0 & 0 & 0 \\
\hline crabapple & 1 & 19.99 & 0.05 & 1 & 0 & 0 & 0 & 0 \\
\hline fig & 1 & 9.01 & 0.11 & 12 & 0 & 1 & 0 & 1 \\
\hline fist fruits & 1 & 19.99 & 0.05 & 1 & 0 & 0 & 0 & 0 \\
\hline Fruit Loops & 1 & 14.99 & 0.07 & 6 & 0 & 0 & 0 & 0 \\
\hline fruits of labor & 1 & 18.98 & 0.05 & 2 & 0 & 0 & 0 & 0 \\
\hline Fruity Pebbles & 1 & 16 & 0.06 & 5 & 0 & 0 & 0 & 0 \\
\hline golden delicious apple & 1 & 19.99 & 0.05 & 1 & 0 & 0 & 0 & 0 \\
\hline Granny Smith apple & 1 & 14.02 & 0.07 & 7 & 0 & 0 & 0 & 0 \\
\hline huckleberry & 1 & 18.98 & 0.05 & 2 & 0 & 0 & 0 & 0 \\
\hline loganberry & 1 & 12 & 0.08 & 9 & 0 & 0 & 0 & 0 \\
\hline mandarin orange & 1 & 9.01 & 0.11 & 12 & 0 & 0 & 0 & 0 \\
\hline marange? & 1 & 19.99 & 0.05 & 1 & 0 & 0 & 0 & 0 \\
\hline mountain cherry & 1 & 13.01 & 0.08 & 8 & 0 & 0 & 0 & 0 \\
\hline navel & 1 & 10.99 & 0.09 & 10 & 0 & 0 & 0 & 0 \\
\hline pecan & 1 & 13.01 & 0.08 & 8 & 0 & 0 & 0 & 0 \\
\hline plantain & 1 & 14.02 & 0.07 & 7 & 0 & 0 & 0 & 0 \\
\hline pomegranate & 1 & 14.99 & 0.07 & 6 & 2 & 1 & 1 & 4 \\
\hline potato & 1 & 8 & 0.12 & 13 & 0 & 0 & 0 & 0 \\
\hline prune & 1 & 9.98 & 0.1 & 11 & 1 & 0 & 0 & 1 \\
\hline pumpkin & 1 & 19.99 & 0.05 & 1 & 1 & 0 & 0 & 1 \\
\hline starfruit & 1 & 18.01 & 0.06 & 3 & 5 & 2 & 2 & 9 \\
\hline
\end{tabular}


APPENDIX C (Continued)

\begin{tabular}{lcccccccc}
\hline \multicolumn{1}{c}{ Fruit } & OD & Rank & OD/R & OP & IF Con & IF Creat & IF NB & IF Total \\
\hline sweet potato & 1 & 5.99 & 0.17 & 15 & 0 & 0 & 0 & 0 \\
washington apple & 1 & 14.99 & 0.07 & 6 & 0 & 0 & 0 & 0 \\
berries & 0 & & 0 & 0 & 2 & 0 & 2 & 4 \\
pepper & 0 & & 0 & 0 & 0 & 1 & 0 & 1 \\
peanut & 0 & & 0 & 0 & 0 & 1 & 0 & 1 \\
flower & 0 & & 0 & 0 & 1 & 1 & 0 & 2 \\
gourd & 0 & & 0 & 0 & 1 & 0 & 0 & 1 \\
eggplant & 0 & & 0 & 0 & 1 & 0 & 0 & 1 \\
dewberry & 0 & & 0 & 0 & 1 & 0 & 0 & 1 \\
lettuce & 0 & & 0 & 0 & 1 & 0 & 0 & 1 \\
turnip & 0 & & 0 & 0 & 1 & 0 & 0 & 1 \\
corn & 0 & & 0 & 0 & 1 & 0 & 0 & 1 \\
onion & 0 & & 0 & 0 & 1 & 0 & 1 & 2 \\
green bean & 0 & & 0 & 0 & 0 & 0 & 1 & 1 \\
zucchini & 0 & & 0 & 0 & 0 & 0 & 1 & 1 \\
\hline
\end{tabular}

(Manuscript received April 9, 2001;

revision accepted for publication September 9, 2001.) 